\title{
High resolution reflection seismic profiling over the Tjellefonna fault in the Møre-Trøndelag Fault Complex, Norway
}

\author{
E. Lundberg ${ }^{1}$, C. Juhlin ${ }^{1}$, and A. Nasuti ${ }^{2,3}$ \\ ${ }^{1}$ Department of Earth Sciences, Uppsala University, Villavägen 16, 75236 Uppsala, Sweden \\ ${ }^{2}$ Department of Petroleum Engineering and Applied Geophysics, Norwegian University of Science and Technology, \\ 7491 Trondheim, Norway \\ ${ }^{3} \mathrm{NGU}$, Geological Survey of Norway, 7491 Trondheim, Norway \\ Correspondence to: E. Lundberg (emil.lundberg@geo.uu.se)
}

Received: 19 December 2011 - Published in Solid Earth Discuss.: 3 February 2012

Revised: 15 May 2012 - Accepted: 20 May 2012 - Published: 13 June 2012

\begin{abstract}
The Møre-Trøndelag Fault Complex (MTFC) is one of the most prominent fault zones of Norway, both onshore and offshore. In spite of its importance, very little is known of the deeper structure of the individual fault segments comprising the fault complex. Most seismic lines have been recorded offshore or focused on deeper structures. This paper presents results from two reflection seismic profiles, located on each side of the Tingvollfjord, acquired over the Tjellefonna fault in the southeastern part of the MTFC. Possible kilometer scale vertical offsets, reflecting large scale northwest-dipping normal faulting, separating the high topography to the southeast from lower topography to the northwest have been proposed for the Tjellefonna fault or the Baeverdalen lineament. In this study, however, the Tjellefonna fault is interpreted to dip approximately $50-60^{\circ}$ towards the southeast to depths of at least $1.3 \mathrm{~km}$. Travel-time modeling of reflections associated with the fault was used to establish the geometry of the fault structure at depth, while detailed analysis of first P-wave arrivals in shot gathers, together with resistivity profiles, were used to define the near surface geometry of the fault zone. A continuation of the structure on the northeastern side of the Tingvollfjord is suggested by correlation of an in strike direction P-S converted reflection (generated by a fracture zone) seen on the reflection data from that side of the Tingvollfjord. The reflection seismic data correlate well with resistivity profiles and recently published near surface geophysical data. A highly reflective package forming a gentle antiform structure was also identified on both seismic profiles. This structure could be related to the folded amphibolite lenses seen on the surface or
\end{abstract}

possibly by an important boundary within the gneissic basement rocks of the Western Gneiss Region. The fold hinge line of the structure is parallel with the Tjellefonna fault trace suggesting that the folding and faulting may have been related.

\section{Introduction}

The Møre-Trøndelag Fault Complex (MTFC), striking ENEWSW, separates the northern North Sea basin system from the Møre and Vøring Basins (Brekke, 2000), and can be traced from the Møre County along the northern margin of the Western Gneiss Region (WGR) towards the Børgefjell Basement Window, where it dies out in a horsetail splay (Roberts, 1998). It consists of several marked major fault segments, e.g. the Hitra-Snåsa Fault (HSF) and the Verran Fault (VF) (Fig. 1). As one of the most prominent fault zones of Norway, both onshore and offshore, the MTFC has been studied frequently. Seismic lines have been recorded mainly offshore, e.g. Sommaruga and Bøe (2002) interpreted several seismic profiles from four inshore/nearshore areas, investigating the geometry and stratigraphy of mainly Jurassic sediments. Seismic profiles on land have focused on the deep crustal structure, e.g. Mykkeltveit (1980) and Hurich (1996). The MTFC has been important in controlling the landscape development both onshore and offshore as established by many authors, e.g. Grunnaleite and Gabrielsen (1995) and Osmundsen et al. (2006), and may still be seismically active today (Olesen et al., 2004), influencing the regional stress 


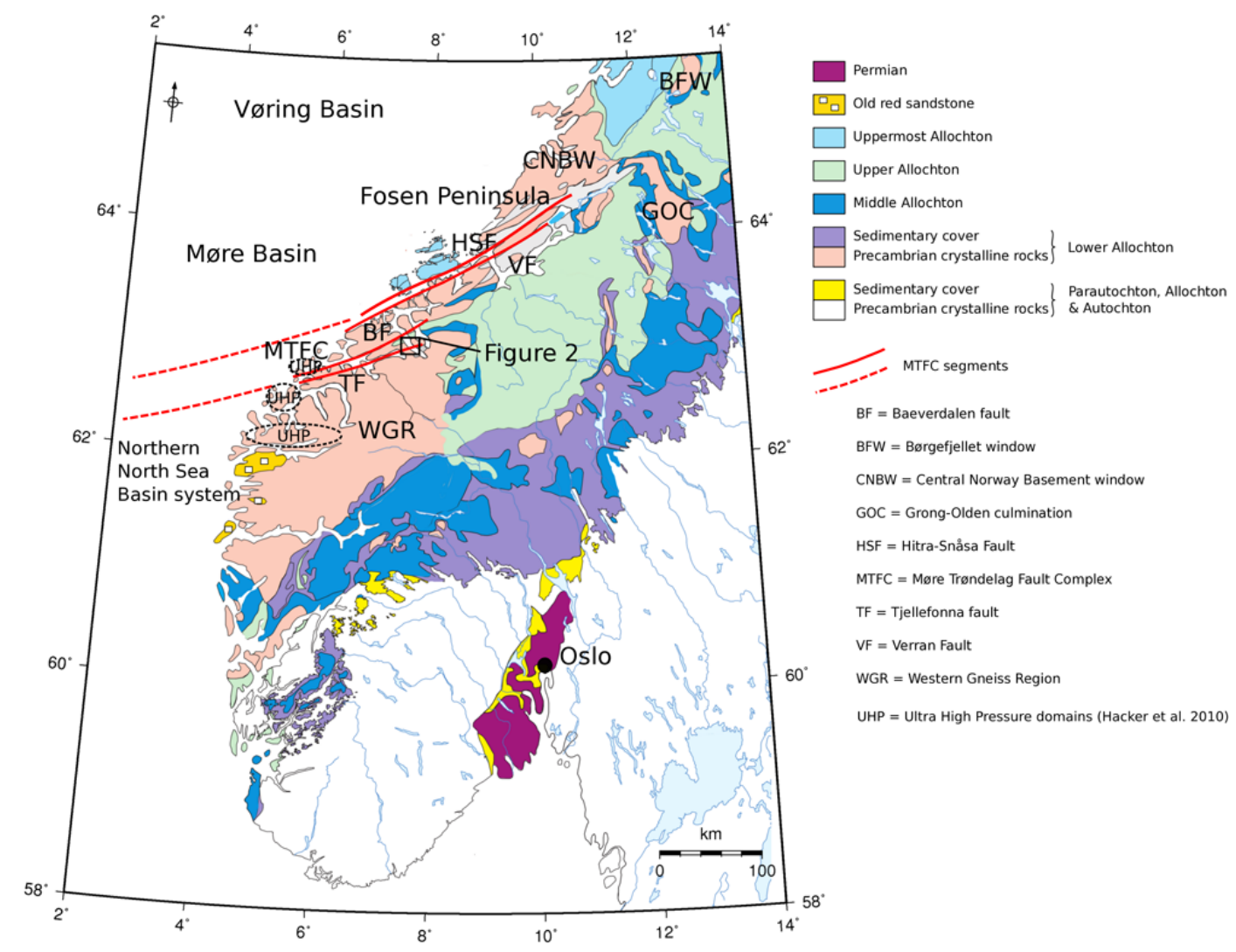

Fig. 1. Tectonostratigraphic map of southern Norway (modified after Mosar et al., 2002) showing the location of the study area in relation to the Western Gneiss Region and the important segments of the Møre-Trøndelag Fault Complex.

pattern of Norway (Pascal and Gabrielsen, 2001). Connecting the deeper structure of MTFC segments with geological observations on the surface is therefore important for understanding seismicity and landslides, as well as the geologi$\mathrm{cal} /$ tectonic history of the region.

Although of major significance, the MTFC had not been investigated by geophysical methods on land until recently, aside from an onshore reflection seismic profile acquired on the Fosen Peninsula (Fig. 1) in the northeast (Hurich and Roberts, 1997). In 2008, an effort was initiated to better understand the nature of one of the onshore segments of the MTFC, the Tjellefonna fault (Fig. 1). The regional scale of the MTFC and its impact on the tectonic setting of middle Norway was studied using potential field data (Nasuti et al., 2012) along with a more detailed study (Nasuti et al., 2011), including DC resistivity soundings, refraction seismic, gravity and magnetic profiles and two reflection seismic profiles with focus on geophysical modeling of the Tjellefona fault and the Baeverdalen fault (Fig. 1). This paper goes into significantly more detail concerning the two reflection seismic profiles crossing the Tjellefonna fault.

The Tjellefonna fault follows a pronounced topographic lineament that runs along Langfjorden and continues past Eidsøra across the Tingvollfjord until Mulvik, and possibly farther northeast. Several fault localities have been mapped along this lineament and together these faults form a coherent fault system (marked in Figs. 1, 2 and 14 by a gray dashed line) paralleling Langfjorden (Redfield and Osmundsen, 2009). Based on apatite fission track data, Redfield et al. (2005a) indicated possible kilometer scale vertical offsets across the Baeverdalen lineament (here Baeverdalen fault, BF, in Fig. 1) and/or the Tjellefonna fault TF. These vertical offset were assumed to be reflecting northwest dipping normal faulting in the last $100 \mathrm{Ma}$ just southeast of the MTFC, separating the high topography to the southeast from lower topography to northwest. The geometry of the Tjellefonna fault at depth was, however, not previously known. In order to better understand the development of the MTFC, it is important to know the geometry of the individual fault segments. In this paper seismic data and resistivity profiles are used to delineate the Tjellefonna fault at depth. The fault appears to separate reflective bedrock to the northwest from less reflective bedrock to the southeast. The strike of the fault appears to be subparallel to the Fold Hinge line of an antiform defined by a reflective package seen on both seismic profiles (S.P. 1 and S.P. 2) at $0.5 \mathrm{~km}$ and $1 \mathrm{~km}$ depth, respectively. 

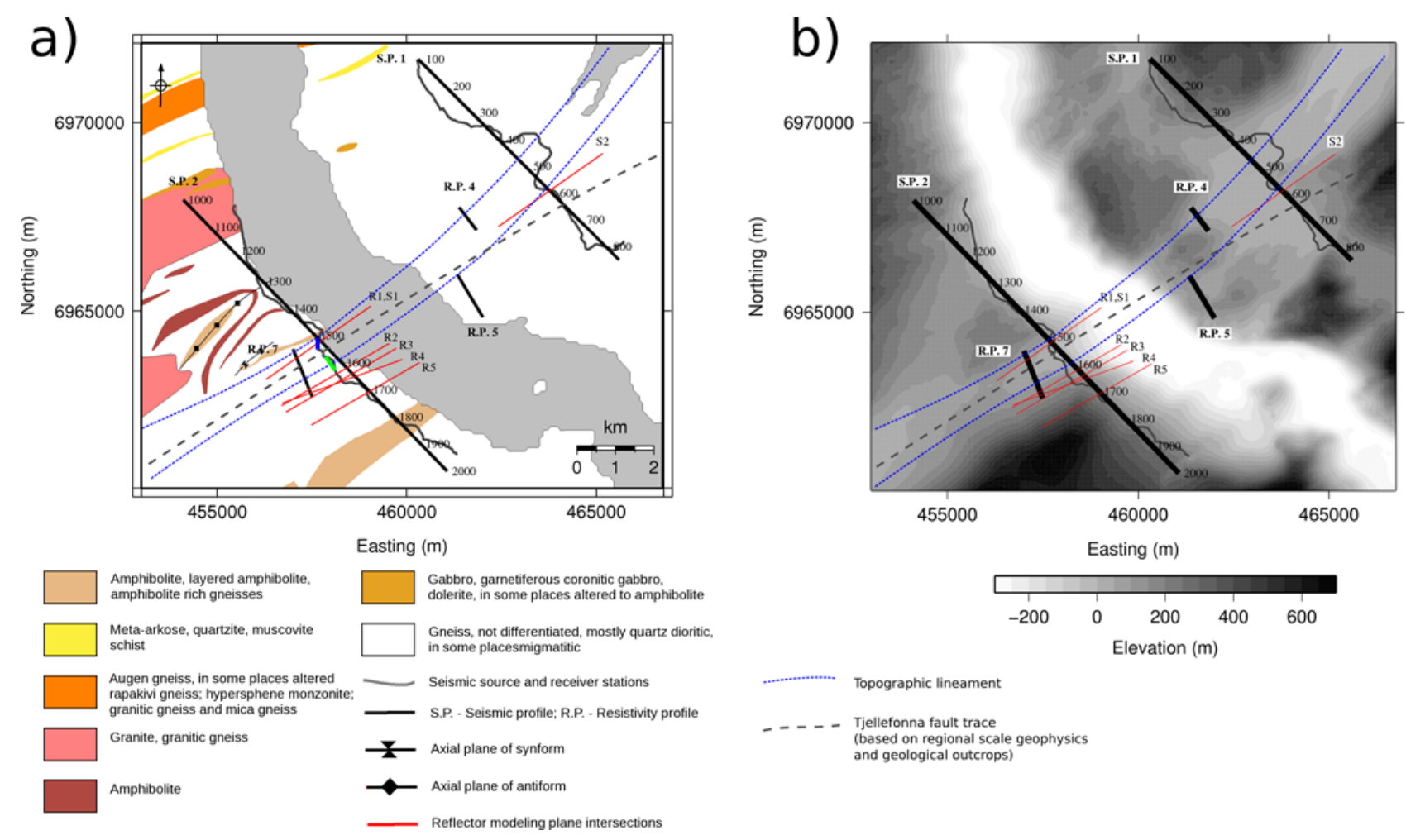

Fig. 2. (a) Simplified geological map after Tveten et al. (1998). S.P - Seismic Profile; R.P - Resistivity Profile; Green zone - LVA; Blue zone - LVB see text for explanation. (b) Topography of the study area. The topographic low is seen between the blue dashed lines on both figures. The thicker gray dashed line indicates the Tjellefonna fault trace based on geological outcrops and regional scale geophysics (Nasuti et al., 2012).

\section{Geological setting}

Our study area is located within the Western Gneiss Region (WGR) of Norway. The WGR is the lowest tectonic unit in the Scandinavian Caledonides (Andersen and Jamtveit, 1990) and is generally a topographic high in Norway displaying pronounced ENE-WSW topographic lineaments (many interpreted as fault zones), following the main Caledonian fabric. The WGR is composed of Fennoscandian gneisses, mainly 1650-950 Ma orthogneisses (Austrheim et al., 2003; Skår and Pedersen, 2003) that were reworked and exhumed in the final stage of the Caledonian Orogeny (i.e. Scandian Phase). The WGR gneisses are structurally overlain by continental and oceanic allochthons. These rocks were downfolded into the basement gneisses and can now be observed as long lobes and tongues extending E-W to ENE-WSW (Braathen et al., 2000; Terry and Robinson, 2003; Hacker et al., 2010). In our study area both gneissic foliation and lobes of Caledonian allochthons, as well as topographic lineaments, extend in the ENE-WSW direction. The exposed rocks are sometimes folded with fold hinge lines directed ENE-WSW with steeply southeast dipping structures showing the same strike direction (Fig. 2). The folded rocks occur on the northwestern side of the Tjellefonna fault trace, while the rocks on the southeastern side show steeper dips.
The WGR experienced high pressure metamorphism in the Silurian-Devonian continent-continent collision and several ultra high pressure (UHP) terranes, surrounded by highpressure rocks, have been identified within the WGR (e.g. Wain, 1997; Hacker et al., 2010). Peak metamorphic temperature and Scandian deformation intensity are both increasing towards the northwest (Hacker et al., 2010). In western Norway, detachment zones separating the lower crust from the middle and upper crust can be observed and these comprise 2 to $3 \mathrm{~km}$ thick mylonites with a complex geometry consisting of anastomosing high strain zones (Andersen and Jamtveit, 1990).

The MTFC probably formed during the Scandian Phase (Grønlie and Roberts, 1989). Main phases of activity include early Devonian sinistral strike-slip, early Permian sinistral transtension, late Jurassic normal to dextral strike-slip faulting (Grønlie and Roberts, 1989; Séranne, 1992; Sherlock et al., 2004) and, presumably, Cenozoic normal dip-slip (Redfield et al., 2005b). These phases reflect the collapse of the Caledonian mountain chain, widespread Permian rifting, late Jurassic rifting of the northern North Sea and the mid Norway margin (Gabrielsen et al., 1999) and Cenozoic uplift of the Norwegian mountains while offshore basins were subsiding (Faleide et al., 2002; Redfield et al., 2005b). 
Table 1. Acquisition parameters.

\begin{tabular}{ll}
\hline Parameter & Value \\
\hline Source & VIBSIST 1000 mechanical source system \\
Source interval & $20 \mathrm{~m}$ \\
Geophones & $28 \mathrm{~Hz}$ single \\
Receiver spacing & $20 \mathrm{~m}$ \\
Instrument & SERCEL 408 UL \\
Active channels & 300 \\
Sample rate & $1 \mathrm{~ms}$ \\
\hline
\end{tabular}

\section{Data acquisition}

The reflection seismic profiles (S.P.) were acquired in June 2008. The seismic profiles extend approximately $7.3 \mathrm{~km}$ (S.P. 1) and $8.9 \mathrm{~km}$ (S.P. 2), respectively, on each side of the Tingvollfjord (Fig. 2). A VIBSIST mechanical source system was used to generate the seismic waves (see e.g. Cosma and Enescu, 2001 for further details). This system has proven to be useful for imaging fault zones, deformation zones and the upper crust in crystalline environments (e.g. Dehghannejad et al., 2010; Juhlin et al., 2010; Juhlin and Lund, 2011; Lundberg and Juhlin, 2011). The system consists of a hydraulic breaking hammer mounted on a tractor or excavator. Although relatively mobile, profiles are generally required to follow roads or trails, normally resulting in crooked recording geometries. This was especially true for S.P. 1 north of the Tingvollfjord and which resulted in a severely crooked profile in the central parts (Fig. 2). Soft ground conditions sometimes reduced the quality of recorded seismograms due to bad coupling between the source and the ground. Some source points also had to be skipped due to wet and soft ground conditions. These included the last $1200 \mathrm{~m}$ of S.P. 1, to the northwest, and also approximately $900 \mathrm{~m}$ in the central parts of S.P. 2. Another reason for skipping source points in some areas was the proximity to buildings and farms housing animals. Gaps in the recording geometry mostly affect the quality of the refraction statics corrections, but they also lower the fold and, thereby, reduce the signal to noise ratio in the final stacked sections. An uneven offset distribution may also effect the processing. In spite of this, the recorded seismic data were of sufficient enough quality to produce interpretable stacks on both sides of the Tingvollfjord. Acquisition parameters are listed in Table 1.

The 2-D-resistivity profiles (R.P. in Fig. 2) were acquired according to the Lund system (Dahlin, 1996). Data were collected with a gradient array configuration with electrode spacing of 10 and $20 \mathrm{~m}$ to map the shallow and deeper parts of the profiles, respectively. The depth penetration is approximately $130 \mathrm{~m}$, with reliable data coverage to approximately $70 \mathrm{~m}$ depth.

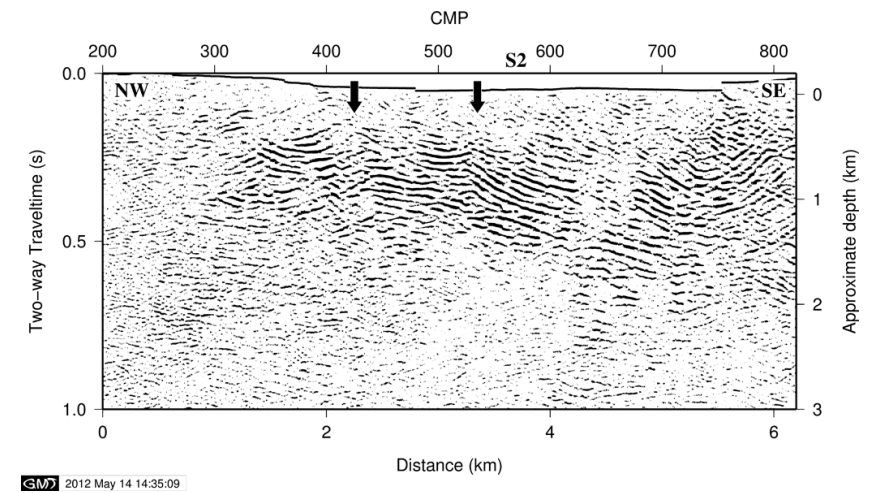

Fig. 3. Final migrated stack of S.P. 1 with marked position of reflection S2 (see also Fig. 8a). Arrows mark sections affected by sharp bends in the recording line (compare with Fig. 2). Elevation marked on top. Length to depth ratio approximately $1: 1$.

\section{Processing}

Careful processing was required due to the seismic lines following crooked profiles and rugged terrain. Especially the northeastern part of S.P. 1 had a large spread in the midpoints in the central part of the profile due to its crookedness (Fig. 2). This large midpoint spread has a significant influence on the possibility to stack reflections coherently. Two sections on S.P. 1 (between CMP 400-450 and 520-550), where the recording line is approximately perpendicular to the stacking line (and hence parallel to structural trends), have clear reduced coherency in the reflections (Fig. 3). To properly image both steeply dipping reflections as expected from the fault zone itself, as well as sub-horizontal reflections from flat lying structures, a dip moveout correction (DMO) is usually required. DMO could, however, not be applied successfully, most likely due to large fold variations along the profiles and the large spread of midpoints for each CMP bin. If DMO is not applied, steeper reflections will stack with a higher normal moveout velocity. In S.P. 2, steep reflections in the southeastern part of the stack were visible when a high normal moveout velocity was applied (Fig. 4b). Since the strongest sub-horizontal reflectivity is observed in the northwestern part of the stack (Fig. 4a), and DMO processing was unsuccessful, we produced two separate stacks of S.P. 2 that were merged before interpretation. The seismic data were stacked first with lower normal moveout velocities, in the range of true bedrock velocities, in order to enhance subhorizontal reflections. For the second stack, higher normal moveout velocities were used in order to enhance the steeply dipping reflections.

Refraction static corrections are usually one of the most important steps of reflection seismic processing in environments where low velocity loose sediments are present on top of high velocity bedrock (e.g. Juhlin, 1995), as is common in the crystalline environments in Scandinavia. However, the skipping of several source points in the central parts of the 


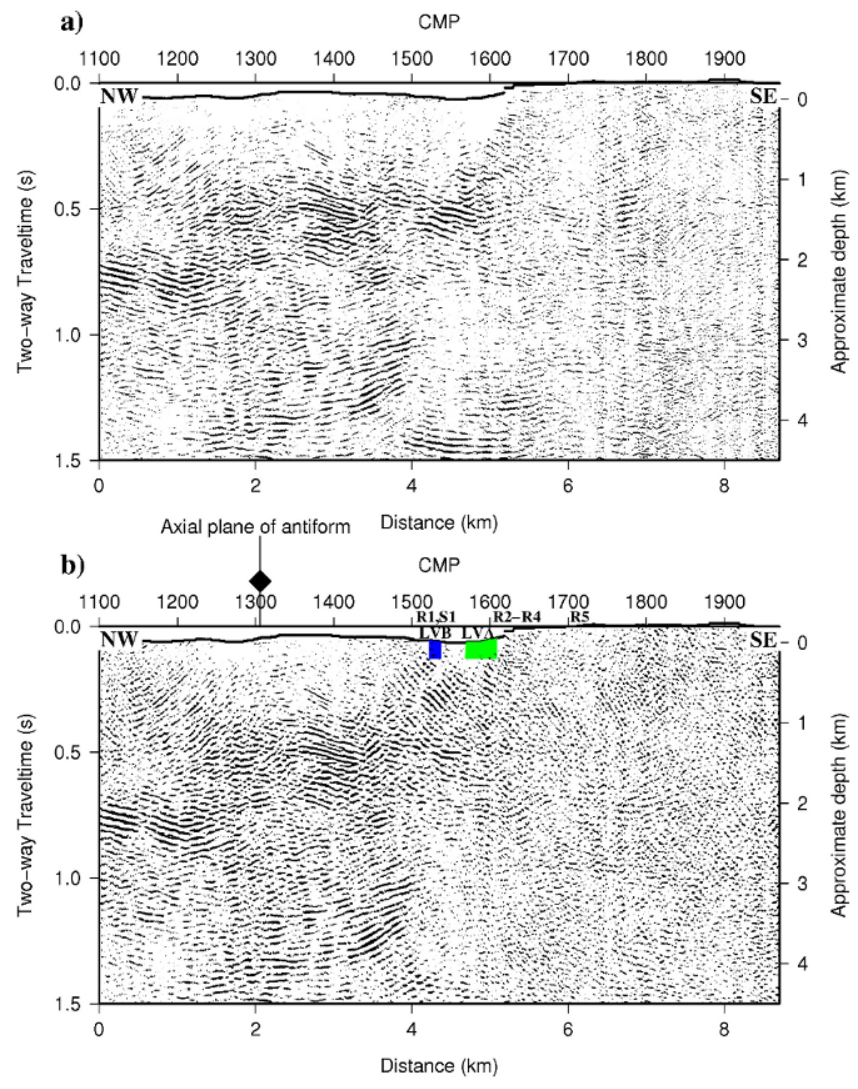

Fig. 4. (a) Final migrated stack of S.P. 2. (b) Final migrated stack of S.P. 2 merged with migrated stack using high stacking velocities. Green zone - LVA; Blue zone - LVB see text for explanation. Reflections S1 and R1-R5 marked. Location of axial plane of antiform from geology map (Fig. 2) also marked. Elevation on top. Length to depth ratio approximately $1: 1$.

profiles, causing large gaps in the source records, reduced the accuracy of the refraction statics calculation for these parts. Such gaps occur between source points 198 and 245, corresponding to CMP:s 1550 to 1635 in S.P. 2 and also in several sections of S.P. 1. These gaps, together with the large spread of midpoints, most likely causes the lower signal to noise ratio on S.P. 1 (Fig. 3). Figures 5 and 6 show examples of shot-gathers and how the pre-stack processing enhanced the signal quality. Reflections are clearer in the processed shotgathers compared to the raw gathers. All processing steps are outlined in Table 2.

One of the benefits of crooked lines with a midpoint spread around the stacking line is that further possibilities for interpretation are available, since the traces map a 3-D volume rather than just a 2-D slice. Therefore, we tested both an azimuthal binning procedure and a cross-dip analysis method, as described in e.g. Lundberg and Juhlin (2011). These tests were designed to improve the coherency of reflections that originate from out-of-the-plane of the profile. The tests, however, did not show any improved image com-
Table 2. Processing steps.

\begin{tabular}{ll}
\hline Step & Parameters \\
\hline 1 & $\begin{array}{l}\text { Decoding raw shot-gathers using shift and stack } \\
\text { procedure }\end{array}$ \\
2 & Geometry check/correction \\
3 & Trace edit \\
4 & Pick first break \\
5 & Refraction statics: floating datum $200 \mathrm{~m}$ \\
& replacement velocity $5100 \mathrm{~m} \mathrm{~s}^{-1}$ \\
6 & Remove 50 Hz noise \\
7 & Spectral equalization: 1525140180 \\
8 & AGC 100 ms window \\
9 & Deconvolution \\
10 & Band-pass filter 1525140180 \\
11 & Remove first arrival energy \\
12 & AGC 100 ms window \\
13 & Residual statics \\
14 & Normal Move Out correction $50 \%$ stretch mute \\
15 & Stack \\
16 & Floating datum statics \\
17 & Band-pass filter 253595120 \\
18 & FX-decon \\
19 & Band-pass filter 253595120 \\
20 & FD-migration: constant velocity $5500 \mathrm{~m} \mathrm{~s}-1$ \\
21 & Band-pass filter 253595120 \\
\hline
\end{tabular}

pared with the standard stacking procedure, indicating that the imaged structures in Figs. 3 and 4 strike nearly perpendicular to the stacking line.

Crooked line recording geometries often result in that reflections in shot-gathers may be difficult to follow since the receiver offsets are often irregular. Reflection travel-time modeling was, therefore, performed to better understand the geometries of reflectors and link the reflections visible in source gathers with reflections in stacked sections and to the near surface. Travel-times were calculated (using a constant velocity ray tracing code, see Ayarza et al., 2000, for details) for different reflector geometries and the resulting travel-times were visually compared with reflections seen in source gathers and stacked sections. The calculated traveltimes with the best-fit to real data provides an approximate geometry and position of the structure causing each modeled reflection. The modeling assumes a planar reflecting surface and a constant bedrock velocity. Neither of these assumptions is expected in the real case, but by changing the dip or the strike of the modeled reflector planes in small increments and comparing the travel-times with the recorded data, a reasonable fit of travel-times could still be achieved, giving us approximate reflector geometries. Since the stacked sections are in 2-D and the modeling uses the 3-D configuration of sources and receivers, there is some room for error in fitting the travel-times with the stacked data. However, since the data are also compared with shot-gathers, the fitting of modeled travel-times will be more sensitive. The travel-time 

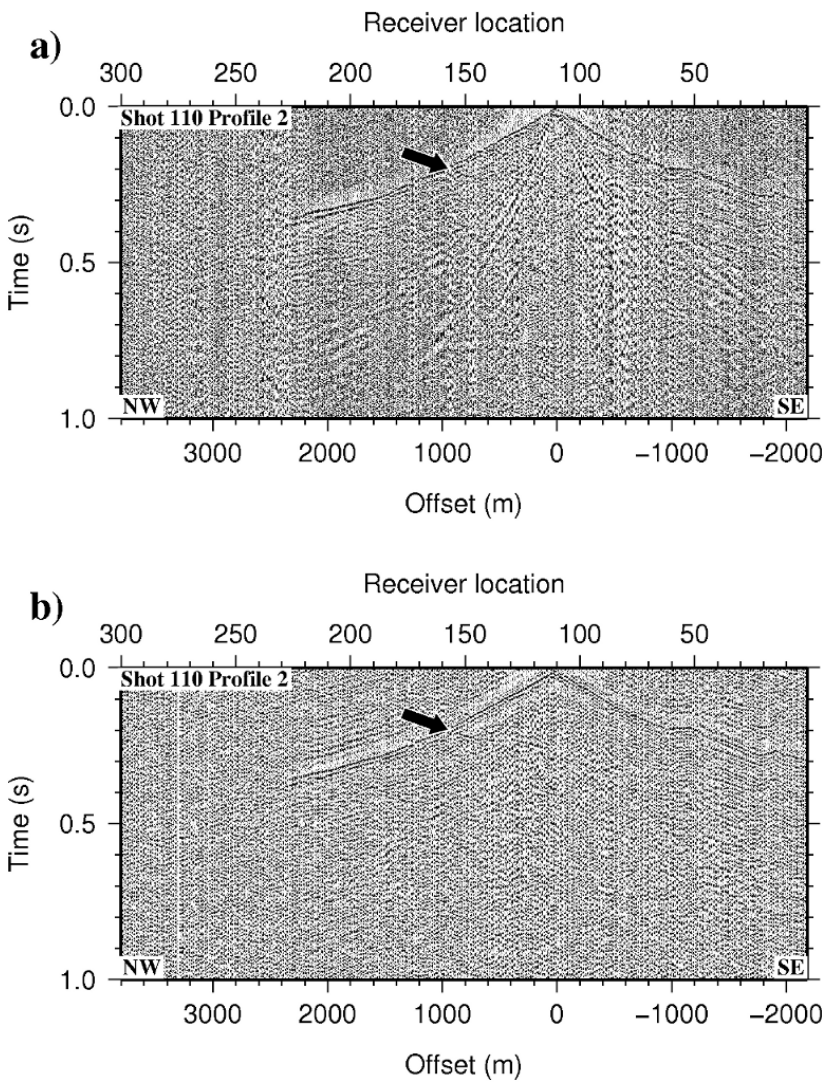

Fig. 5. (a) Raw shot-gather (agc $100 \mathrm{~ms}$ window and high pass filter (10 20) was used) from S.P. 2. (b) The same shot-gather processed until step $10+$ step 12 and 17. Black arrow marks reflection more clearly seen in the processed shot-gather.

modeling is generally more sensitive to the dip of the modeled reflector plane as compared to the strike. The chosen strike directions can be shifted at least $5^{\circ}$ with results still in a reasonable fit to the recorded data. Using appropriate strikes and dips, the corresponding modeled planar surfaces for each reflection (R1-R5) can be projected onto the geological map (Fig. 2). A constant bedrock velocity of $5200 \mathrm{~m} \mathrm{~s}^{-1}$ was used for all modeling. The reflection modeling employed also allows for calculating reflection coefficients and reflection depth points. These calculations have been used for interpreting the origin of the reflections and the depth extent of the reflectors.

For the 2-D resistivity profiles, we processed and inverted the data using the RES2DINV (version 3.55) software (Loke, 2004). This software lets the operator have full control on data quality, giving the possibility to remove bad data points to improve overall data fit. The measured apparent resistivities with different electrode configurations were converted into 2-D true resistivity profiles. Further details can be found in Nasuti et al. (2009).
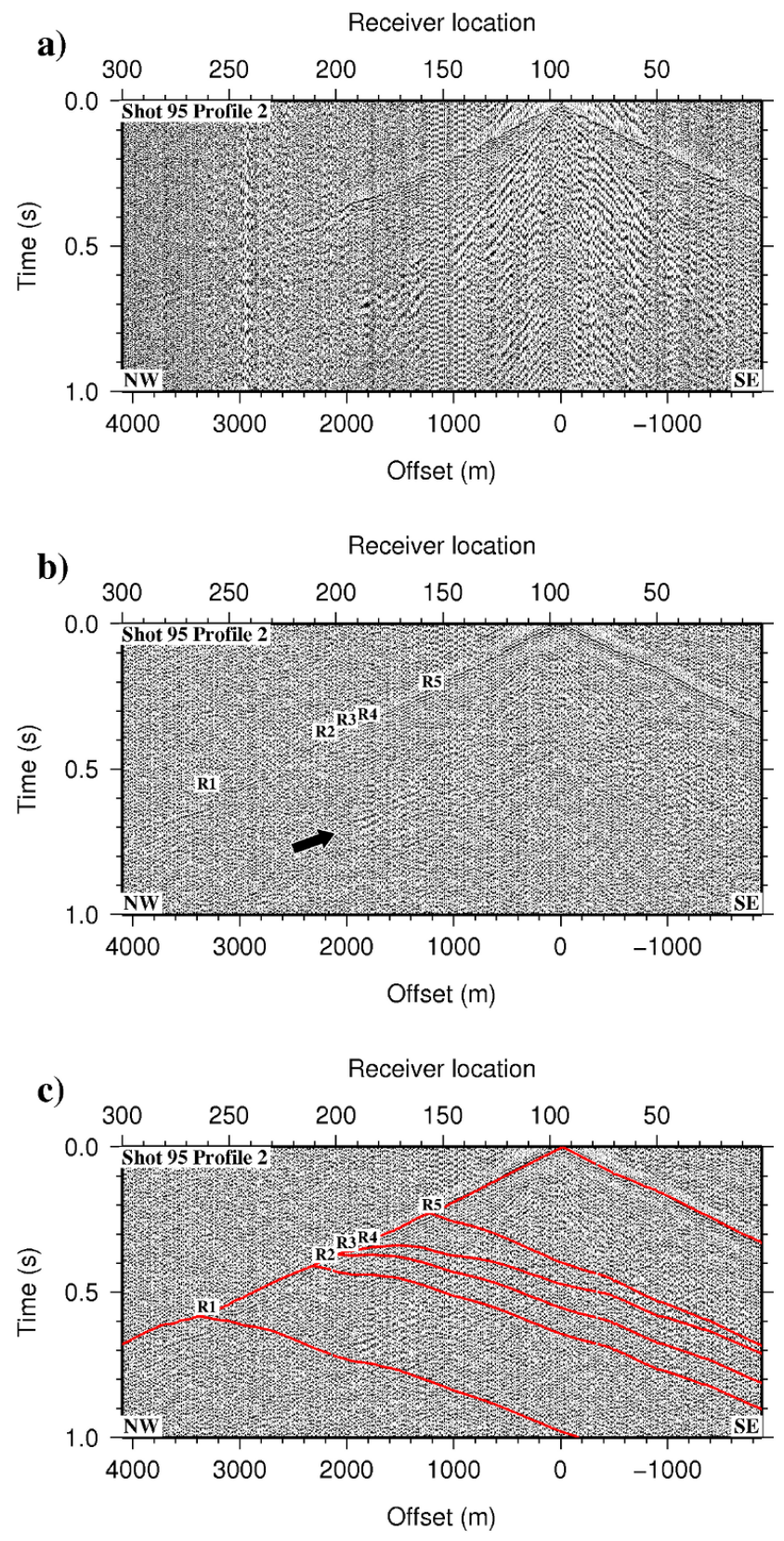

Fig. 6. (a) Raw shot-gather (agc $100 \mathrm{~ms}$ window and high pass filter (10 20) was used) from S.P. 2. (b) The same shot-gather processed until step $10+$ step 12 and 17 . The northwest dipping reflection marked with black arrow correspond to the reflections seen between CMP 1750 and 1800 at about $0.5 \mathrm{~s}$ TWT in the stacked section (Fig. 4a). (c) The processed shot-gather with calculated traveltimes for reflections R1-R5 plotted.

\section{Results}

\subsection{Stacked sections}

The strongest reflectivity in S.P. 2 (Fig. 4) forms a gentle antiform between CMP 1100 and 1600 with the hinge 

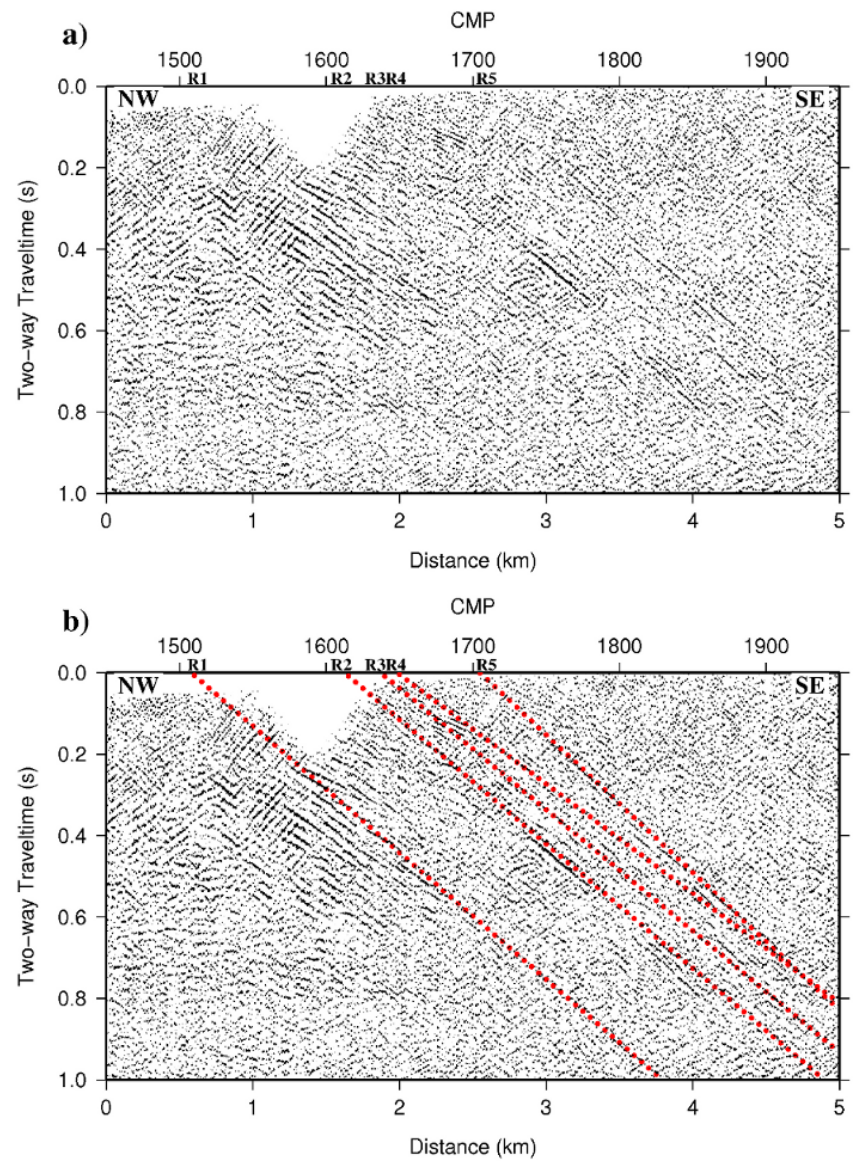

Fig. 7. Parts of unmigrated stack of S.P. 2 using high stacking velocities. (a) Without and (b) with calculated travel-times for reflections R1-R5 plotted.

located close to CMP 1300 in the near surface. The fold axis from geological map is well correlated with the fold axis in the seismic section (Fig. 2). In the southeastern part of S.P. 2, several steeply southeast dipping reflections are visible and seem to project to the surface between CMP 1500 and 1700. Travel-time modeling of these reflections has been performed. Reflections R1-R5 are all visible on shot 95 from S.P. 2 (Fig. 6), however, additional shot-gathers have been used for constraining the modeled reflector geometry. The calculated travel-times are marked in Fig. $6 \mathrm{c}$ and in the unmigrated stacked section (Fig. 7b). Results of the travel-time modeling are given in Table 3. The surface projections of each reflection with the appropriate strike are also marked on the geological map (Figs. 2 and 14). The steep reflection $\mathrm{R} 1$ seems to extend down to about $0.9 \mathrm{~s}$, or approximately $1.3 \mathrm{~km}$ (using a bedrock velocity of $5200 \mathrm{~m} \mathrm{~s}^{-1}$ and a dip of $55^{\circ}$ ), in the unmigrated section (Fig. 7). This depth coincides with the approximate maximum depth to where a reflection with that geometry can be traced without extending the existing seismic profile to the southeast. Reflections R3 and R4 are not as well correlated in the stacked section. This
Table 3. Modeling results.

\begin{tabular}{ccc}
\hline Reflector & Strike & Dip \\
\hline R1 & 55 & $55 \mathrm{SE}$ \\
R2 & 60 & $55 \mathrm{SE}$ \\
R3 & 60 & $53 \mathrm{SE}$ \\
R4 & 70 & $50 \mathrm{SE}$ \\
R5 & 60 & $65 \mathrm{SE}$ \\
\hline
\end{tabular}

is due to that these reflections are best seen in the near surface on shot-gathers and in deeper parts in the stacked section, which makes the fitting of travel-times more difficult. Northwest dipping reflectivity indicated by a black arrow is seen in Fig. 6b. This reflectivity corresponds to the reflectivity between CMP 1750 and 1800 at approximately $0.5 \mathrm{~s}$ in S.P. 2 (Fig. 4a) and may be the continuation of the reflective package, forming the antiform further northwest.

The stack from S.P. 1 (Fig. 3) shows a disrupted reflective package that seems to form a folded structure, resulting in an antiform with a hinge around CMP 450 at about $0.2 \mathrm{~s}$ (ca. $0.5 \mathrm{~km}$ depth). This structure can be defined between CMP 300-700. The disruptions in this reflective package are most likely caused by the sharp bends in the acquisition line (Fig. 2).

\subsection{Source-gather analysis and modeling}

Two divergent reflections come to the surface in the central parts of both reflection profiles (Fig. 8). These reflections appear only in a few shots and are most visible at offsets of about $2 \mathrm{~km}$. Reflection S1 on S.P. 2 is visible between receivers 215 and 255 with a gap between receivers 225 and 240. Reflection S2 on S.P. 1 is only visible for about $300 \mathrm{~m}$ (on 15 geophones). It is therefore difficult to perform accurate travel-time modeling of these reflections. Modeling, however, clearly shows that S1 is not a P-P reflection from a reflector with a similar geometry to the R1-R5 reflectors. In fact it was not possible to find any suitable reflector geometry that could fit the travel-times of S-1 when a P-P reflection was considered. Therefore, other options had to be tested. Figure 9 shows calculated travel-times for two different scenarios. In Fig. 9, travel-times from a P-P reflection from an $80^{\circ}$ southeast dipping reflector are compared with travel-times from a P-S converted reflection from a reflector with the same geometry as the R1 reflection. The P-S converted reflection travel-times most closely fit the real data (Fig. 9c). Angle dependent reflection coefficients were also calculated in order to understand why the P-S reflection is most apparent in the observed offset range and, perhaps also, to provide a clue as to the origin of the reflection. P-P and P$\mathrm{S}$ reflections from two fault zones (FZ), with different $V_{\mathrm{p}} / V_{\mathrm{S}}$ ratios, and from a mafic rock are compared in Fig. 10. The calculations are based on the same geometry as used for reflection R1 with rock parameters defined in Table 4. The 2-D 
a)

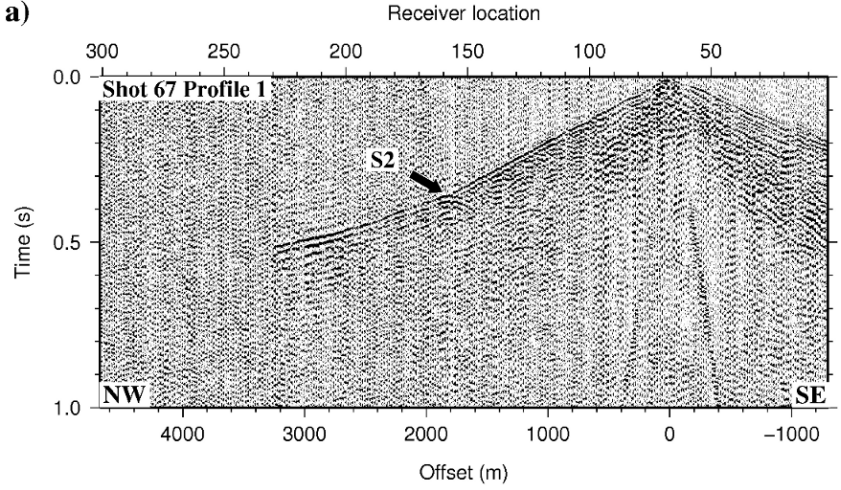

b)

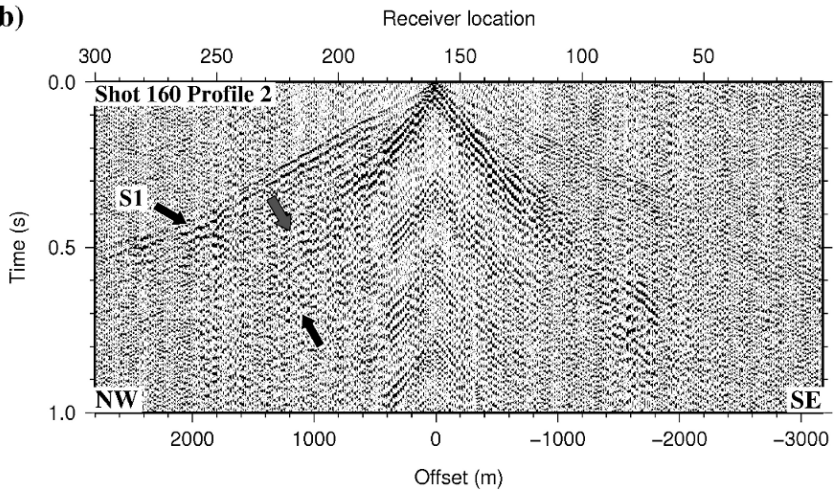

Fig. 8. P-S converted reflections (S2 and $\mathrm{S} 1)$ in raw shot-gathers on both S.P. 1 (a) and S.P. 2 (b). Dark gray arrow indicates where surface waves disappear.

sketch (Fig. 11) of the P-P and P-S ray tracing (although the 3 -D geometry was used in the calculations) illustrates the different ray paths used. The angle of reflection is smaller than the incidence angle for the P-S converted ray path, since the $\mathrm{S}$ wave velocity is lower than the $P$ wave velocity. The seismic velocities are typical values from laboratory measurements on rock samples collected along S.P. 2 (A. Nasuti, unpublished data, 2009). The slowest velocity (perpendicular to foliation) was used and the host rock is assumed to be intact gneiss. Densities are averages from rock samples collected by Biedermann (2010). The magnitude of the reflection coefficient is used for easier comparison of both positive and negative polarity reflections. In the interval where the P-S converted reflection is visible (receivers $215-255$ ) a P-S reflection from a fault zone with a high $V_{\mathrm{p}} / V_{\mathrm{s}}$ ratio (1.8) has amplitudes almost as high as a P-P reflection from a mafic rock. The reflection coefficient from a P-P reflection from a fault zone with a high $V_{\mathrm{p}} / V_{\mathrm{s}}$ ratio (1.8) in the same interval is low, implying that it is unlikely to see the P-P reflection in this interval, but the P-S reflection should be strong. Since the P-S converted travel-time modeling fits the real data better than a steeply dipping P-P reflection and that a stronger $\mathrm{P}-\mathrm{S}$ reflection than a P-P reflection can be expected with this reflector geometry, it is reasonable to assume that $\mathrm{S} 1$ is the
P-S converted reflection from the same reflector as R1 and that these reflections originate from a fault zone boundary.

In between reflections R1 and R2 (Fig. 4b), two zones display a sharp delay in first arrival times indicating lower velocity in these areas (Fig. 12). We name these zones lowvelocity zone A and B (LVA and LVB). The delay in LVB is $0.025 \mathrm{~s}$ over a distance of $160 \mathrm{~m}$ and the delay in LVA is $0.040 \mathrm{~s}$ over a distance of $390 \mathrm{~m}$ (Fig. 12). These zones are clearly visible on many shot gathers, and their respective positions correlate well between shot-gathers from the northwestern side of the zones. However, when comparing the position of these zones on shots from the opposite (southeast) side, a slight shift of the positions towards southeast occurs. The locations from shot-gather 302 (Fig. 12) was used to outline these zones on the stacked sections. In addition to significant delays in the first arrivals across these zones, the ground roll also disappears when approaching these zones. This effect is clearly seen in shot 302 where ground roll disappears around receiver 265 (Fig. 12) and in shot 160 (Fig. 8b) where ground roll disappears around receiver 210 , corresponding approximately to the southeastern boundary of LVA. No sources were activated in LVA due to soft ground conditions.

\subsection{Resistivity profiles}

The resistivity profiles are interpreted here for the purpose of correlating the observed reflections and the shallow subsurface. Two not previously published resistivity profiles (R.P. 4 and R.P. 5 in Fig. 13) are marked with some possible fault locations. In the inverted profiles, relatively low-resistive zones may indicate fractured and/or water saturated bedrock, while more resistive zones are diagnostic of intact bedrock. Particularly low resistivity (i.e. lower than $1000 \Omega \mathrm{m}$ ) characterizes clay-filled fractures and, consequently, also fault gouge (e.g. Ganerød et al., 2008). R.P. 4 is located in the topographic low and shows a sharp lithological contrast (see Figs. 2 and 14). R.P. 5 has three low resistivity zones marked (P1-P3). R.P. 7 (Nasuti et al., 2011) has now been reinterpreted based on the correlation with the reflection seismic profiles. The northernmost zone (marked P6 in Fig. 13) has been extended with a southeasterly dip. P6 shows a direct correlation with reflections R1, S1 and S2 in the seismic sections (see Figs. 13 and 14). P3 on R.P. 5 possibly correlates with P4 on R.P. 7 (see Figs. 13 and 14).

\section{Discussion}

The main topographic low and the Tjellefonna fault trace (from regional scale geophysics and outcrops) crosses S.P. 2 between CMPs 1500 and 1600, see Figs. 2 and 14. The most likely reflections that may be associated with the Tjellefonna fault are, therefore, reflections R1/S1 and R2. The overall reflectivity pattern can also be used to separate reflective rock 
a)

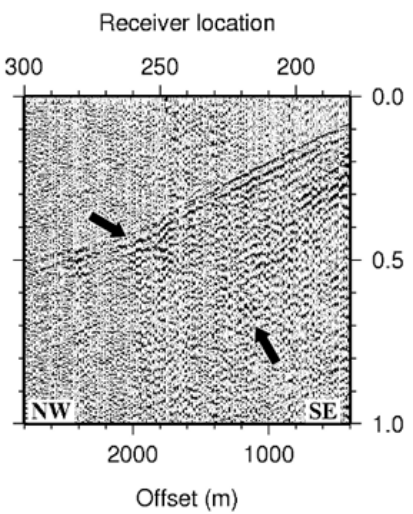

b)

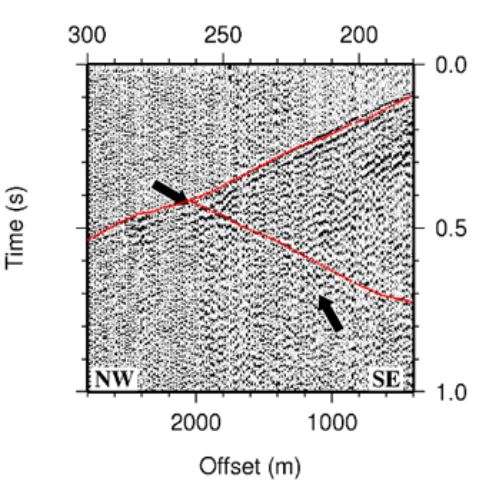

c)

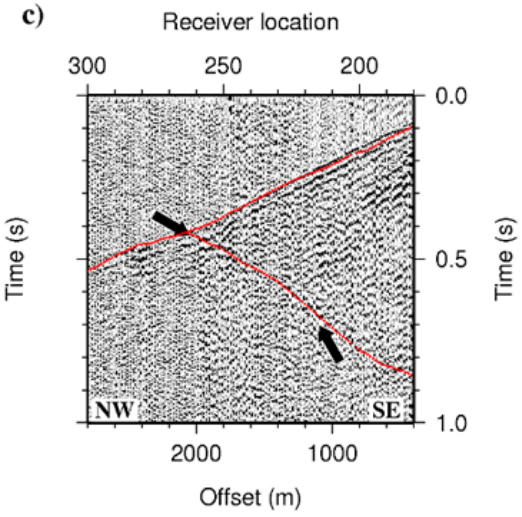

Fig. 9. Comparison of travel-time modeling of reflection S1. (a) without travel-time modeling (b) P-P reflection from a steeply dipping boundary strike $55^{\circ}$ and dip $80^{\circ}$. (c) P-S reflection from a boundary with strike $55^{\circ}$ and dip $55^{\circ}$ (same geometry as for reflection R1).

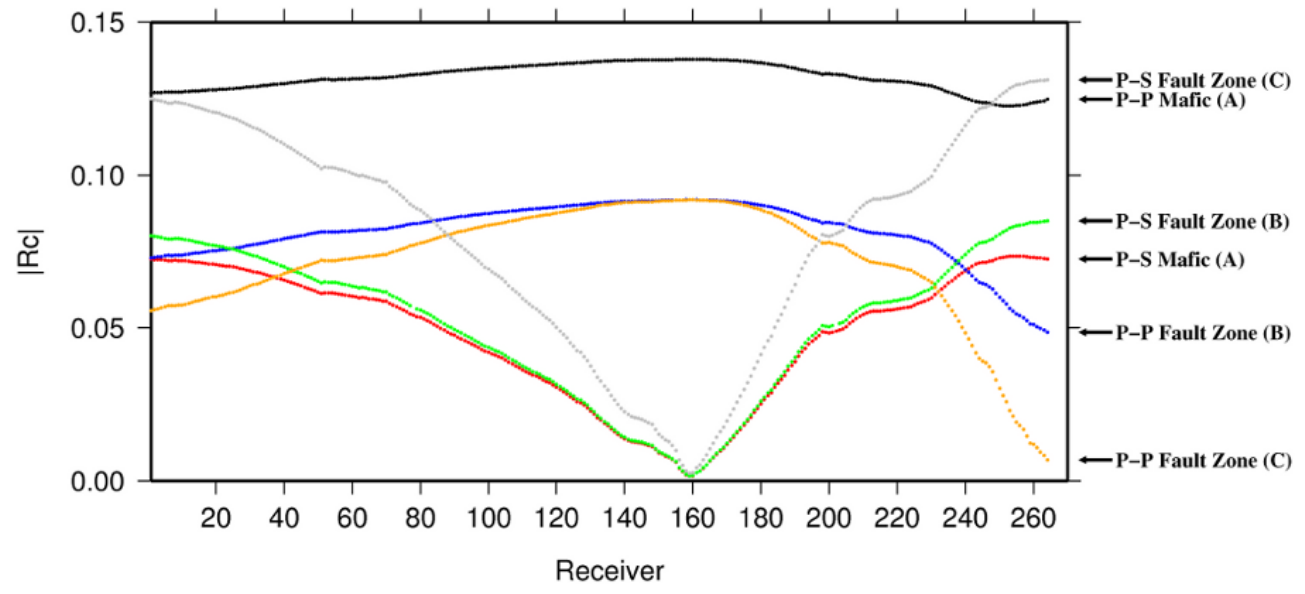

Fig. 10. Comparison of magnitude of reflection coefficient $(|\mathrm{Rc}|)$ for different reflecting boundaries. Geometry of boundary as for reflection $\mathrm{R} 1$ (strike $55^{\circ}$ and dip $55^{\circ}$ ) and properties of rocks as defined in Table 4 .

Table 4. Rock parameters used for calculating reflection coefficients. Velocities are typical values from laboratory measurements on rock samples collected along S.P. 2 (A. Nasuti, unpublished data, 2009). The slowest velocity (perpendicular to foliation) was used and the host rock is assumed to be an intact gneiss. Densities are averages from rock samples collected by Biedermann (2010).

\begin{tabular}{llll}
\hline & $\begin{array}{l}\text { A. Gneiss (1)/ } \\
\text { Mafic (2) }\end{array}$ & $\begin{array}{l}\text { B. Gneiss (1)/ } \\
\text { Fault Zone (2) }\end{array}$ & $\begin{array}{l}\text { C. Gneiss (1)/ } \\
\text { Fault Zone (2) }\end{array}$ \\
\hline$V_{\mathrm{P} 1}\left(\mathrm{~m} \mathrm{~s}^{-1}\right)$ & 4400 & 4400 & 4400 \\
$V_{\mathrm{S} 1}\left(\mathrm{~m} \mathrm{~s}^{-1}\right)$ & 2750 & 2750 & 2750 \\
$V_{\mathrm{P} 1} / V_{\mathrm{S} 1}$ & 1.6 & 1.6 & 1.6 \\
Density $\left(\mathrm{kg} \mathrm{m}^{-3}\right)$ & 2700 & 2700 & 2700 \\
$V_{\mathrm{P} 2}\left(\mathrm{~m} \mathrm{~s}^{-1}\right)$ & 5600 & 3800 & 3800 \\
$V_{\mathrm{S} 2}\left(\mathrm{~m} \mathrm{~s}^{-1}\right)$ & 3200 & 2375 & 2100 \\
$V_{\mathrm{P} 2} / V_{\mathrm{S} 2}$ & 1.75 & 1.6 & 1.8 \\
Density2 $\left(\mathrm{kg} \mathrm{m}^{-3}\right)$ & 2800 & 2600 & 2600 \\
\hline
\end{tabular}

to the northwest of CMP 1550 in S.P. 2 from less reflective rock to the southeast. This difference in reflectivity may be due to a more suitable reflector geometry to the northwest (i.e. flat lying structures), as compared to the steeper structures towards southeast. This change of geometry can be explained by the presence of a steep fault zone. Our modeling indicates that $\mathrm{R} 1$ is a P-P reflection and $\mathrm{S} 1$ a $\mathrm{P}-\mathrm{S}$ reflection off a fault zone, assuming reasonable input was used in the modeling and the reflection coefficient calculations. Fracturing and chemical alteration of rock results in lower $V_{\mathrm{p}}$ and $V_{\mathrm{s}}$ and in an increase in the $V_{\mathrm{p}} / V_{\mathrm{s}}$ ratio (e.g. Moos and Zoback, 1983). The $V_{\mathrm{p}} / V_{\mathrm{s}}$ ratio seems to be the most important factor for explaining the strong P-S reflection and the missing (below noise level) P-P reflection in the traces close to where the reflector intersects the surface. At the offsets of interest, fracture zone (C), with a $V_{\mathrm{p}} / V_{\mathrm{s}}$ ratio of 1.8 , clearly shows a much larger P-S reflection coefficient than fracture zone (B), with a $V_{\mathrm{p}} / V_{\mathrm{s}}$ ratio of 1.6 (Fig. 10). Note that the host gneissic rock is assumed to have a $V_{\mathrm{p}} / V_{\mathrm{s}}$ ratio of 1.6. The reflection coefficient of a P-S reflection from the mafic rock is almost 


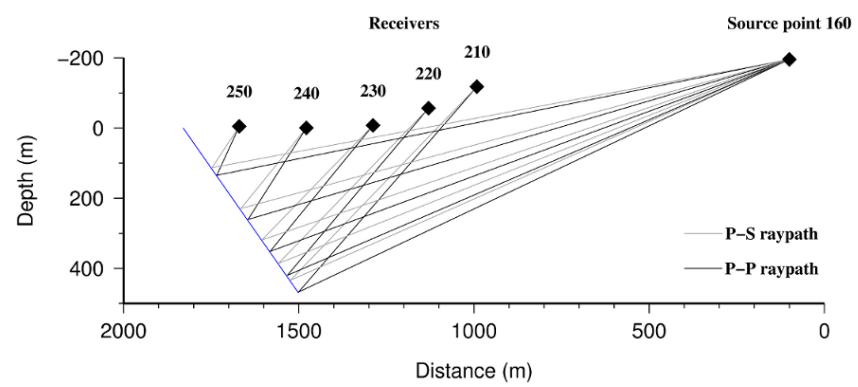

Fig. 11. 2-D sketch of the selected ray paths for a model with a plane dipping $55^{\circ}$. The angle of reflection is larger than the incidence angle for the P-S converted ray path, since the $\mathrm{S}$ wave velocity is lower than the $\mathrm{P}$ wave velocity. The reflection point for receiver 210 is located at approximately $425 \mathrm{~m}$ depth for a P-S converted reflection.

at the level of the P-S reflection from fracture zone (B), but the modeled strong $\mathrm{P}-\mathrm{P}$ reflection for the mafic rock is not observed in the data (Fig. 8b). Therefore, we interpret the reflector generating reflections $\mathrm{R} 1 / \mathrm{S} 1$ to be a fracture zone with a high $V_{\mathrm{p}} / V_{\mathrm{s}}$ ratio (fluid filled). The reflection point for the reflected energy of S1 at receiver 210 at about $0.7 \mathrm{~s}$ TWT can be calculated. It is located at a depth of approximately $425 \mathrm{~m}$ and indicates the minimum depth extent of the fracture zone. A possible deeper extension of the fault zone to approximately $1.3 \mathrm{~km}$ is suggested when tracing the P-P reflection in the stacked section.

Reflection S2 on S.P. 1 has a very similar character as to S1 on S.P. 2 and is located in the strike direction of S1 (Fig. 2). The same reflector geometry as for R1/S1 gives a reasonable fit for a P-S converted reflection, but a corresponding P-P reflection is not seen in the stacked section. If the reflector is steeper on this profile it may explain why it is not imaged on the stacked section. Another possibility is that S.P. 1 is too short towards the southeast to properly image the deeper part of the fault zone. It is reasonable to assume that the Tjellefonna fault continues in the strike direction of reflection S1. The strike of the fault is then also in agreement with previous large scale interpretation of potential field data (see Fig. 7 in Nasuti et al., 2012).

The low velocity zones LVA and LVB are interpreted from shot-gathers without refraction static corrections. Different possible causes for the delays must, therefore, be considered: (1) an increase in the thickness of the low velocity sedimentary cover; (2) a decrease in velocity in the sedimentary cover; (3) a decrease in the bedrock velocity. A decrease in bedrock velocity would be expected across a fracture zone. The lack of ground roll in these zones may be due to changing properties in the sedimentary cover. Alternatively, if the bedrock is heavily fractured and water filled, then ground roll will also be largely attenuated across such a zone. If the delays are caused only by the sedimentary cover, then a quick recovery of the arrival times outside of the zones is expected.

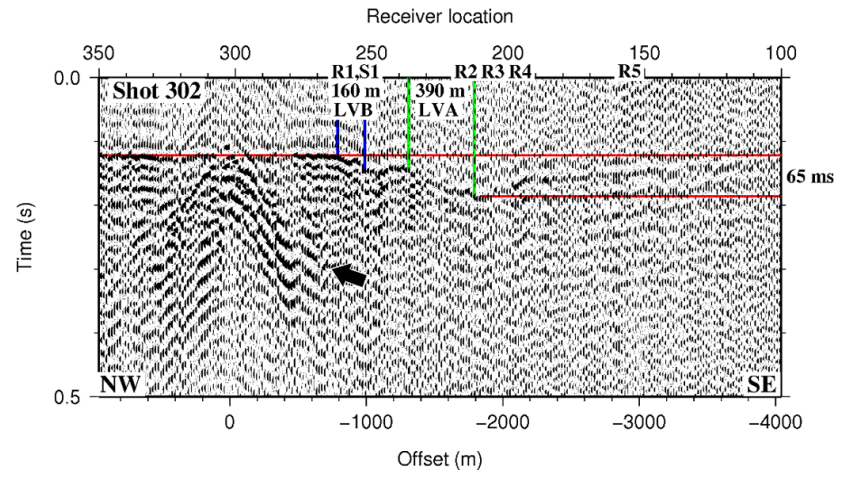

Fig. 12. Shot-gather 302 from S.P. 2 plotted using a reduction velocity of $5000 \mathrm{~m} \mathrm{~s}^{-1}$ and without refraction statics correction. Two zones display a sharp delay in the first arrivals and are marked as LVA and LVB. Total accumulated delay is $65 \mathrm{~ms}$ across the two zones. Southeast dipping reflections S1, R1-R5 not seen in this shot-gather, are marked. Black arrow indicates where surface waves disappear.

This can be seen in Fig. 12 between receivers 195 to 210 . There is, however, some delay that is not recovered until at least receiver 100. This remaining delay is about $0.040 \mathrm{~s}$ and is more likely due to decreased bedrock velocity. The soft ground conditions found between receiver 198 and 245 during acquisition could indicate that LVA is due only to changes in the sediment cover properties. The remaining delay is, however, larger than the delay in LVB alone $(0.025 \mathrm{~s})$ and, therefore, some delay caused by lower bedrock velocity in LVA is also required to fully explain the large total delay. Most likely, LVA and LVB are both low velocity zones with a decreased bedrock velocity, indicating fractured bedrock.

Nasuti et al. (2011) showed the existence of south dipping or sub-vertical fault zones (R.P. 7) approximately $700 \mathrm{~m}$ to the southwest (Figs. 2 and 13). Refraction seismic and resistivity profiles indicated two well correlated low velocity/fractured zones. LVA correlates fairly well with the central fracture zone indicated by Nasuti et al. (2011), here P5 (Figs. 13 and 14). The width of LVA is about $390 \mathrm{~m}$, while Nasuti et al. (2011) interpreted the central fault zone to be in the 100-200 $\mathrm{m}$ range. The width of LVA may be influenced by the sediment cover and the true width may be less than $390 \mathrm{~m}$. LVB correlates very well with the northwestern most low resistivity zone, here P6 (Figs. 13 and 14). A southeasterly dip of LVB seems to correlate with a possible extension of the low resistivity zone. The width of LVB $(160 \mathrm{~m})$ is not influenced by a thick sediment cover, as is LVA, and the mapped width is probably close to the true width of the fractured bedrock. The width of LVB is also similar to the width of the low resistivity zone P6 on R.P. 7. A further consequence of our extended interpretation is that the fracture zones from the resistivity profiles may be connected at a deeper level, and that they converge into a single wider fault zone causing the reflectivity seen in the reflection seismic 

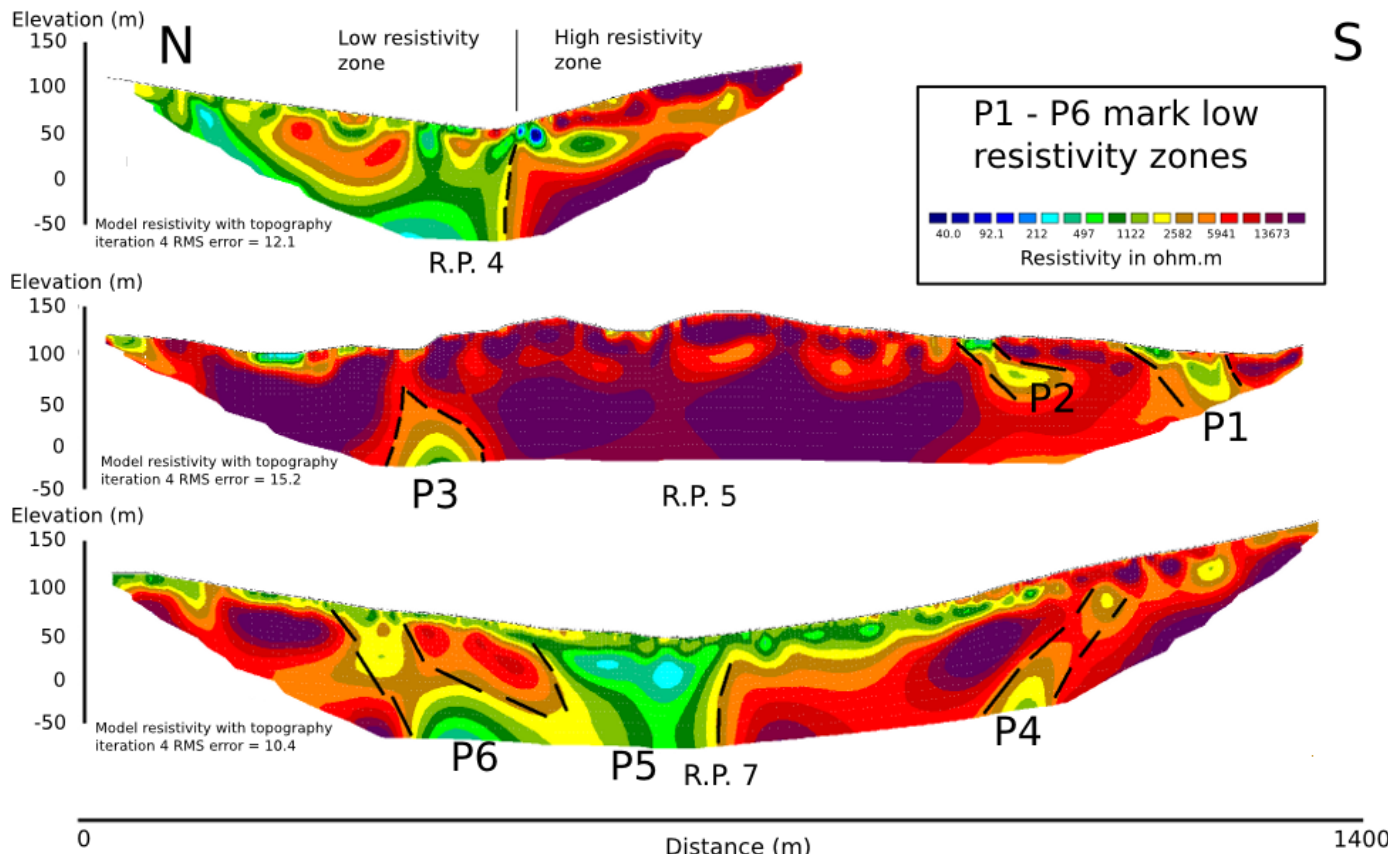

Fig. 13. Resistivity profiles 4, 5 and 7 (R.P. 7 reinterpreted from Nasuti et al., 2011). For low resistivity zones marked P1-P6 see text for discussion. Length to depth ratio approximately $1: 1$.

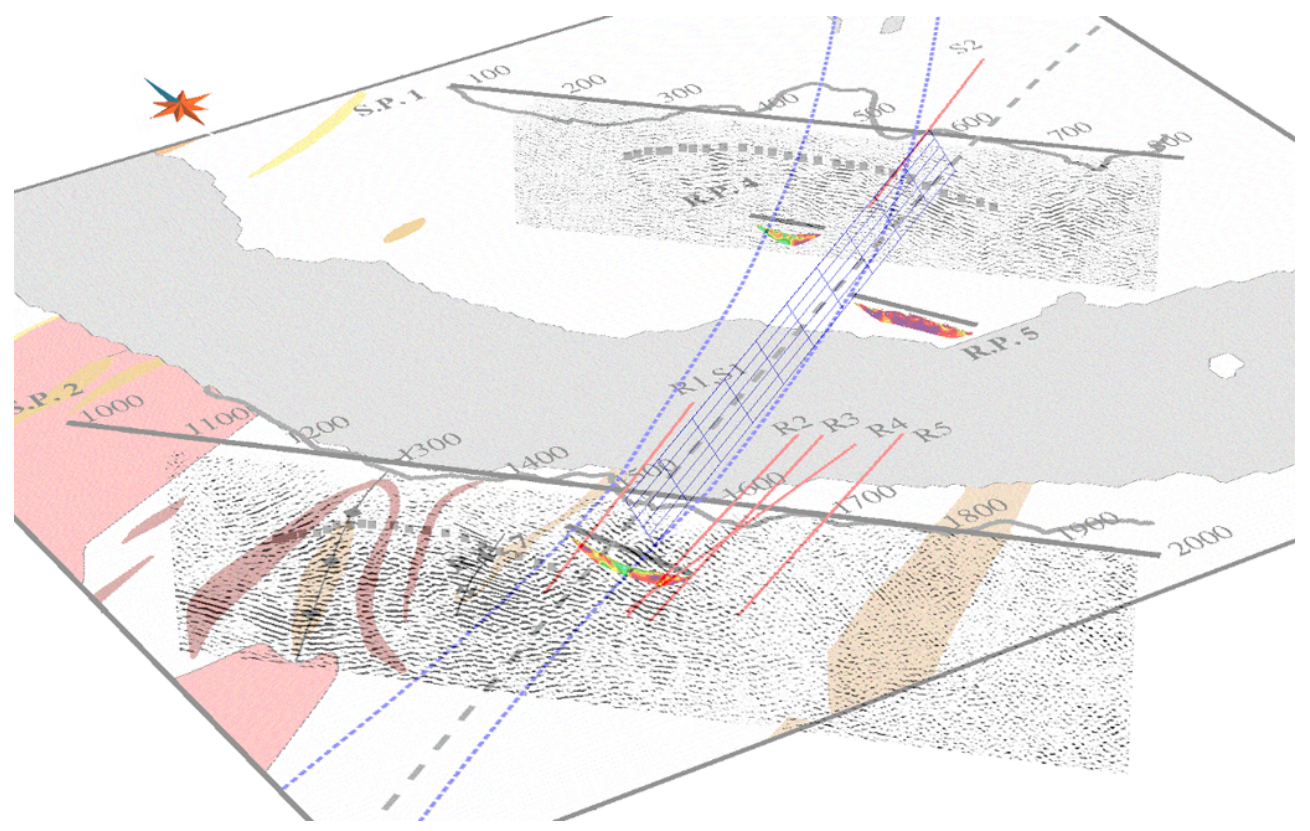

Fig. 14. Seismic profiles 1 and 2 and resistivity profiles 4,5 and 7 plotted with geology in 3-D perspective view. Blue dashed lines indicates topographic lineament and red solid lines mark reflections S2, S1/R1-R5. See Fig. 2 for locations. The blue plane indicates the modeled fault plane with strike $55^{\circ}$ and dipping $55^{\circ}$ towards south east. The plane extends to $400 \mathrm{~m}$ depth in this figure. Antiform structures are enhanced with gray squares. The fold hinge line seems to be subparallel to the fault plane.

stack. P5 and P6 appear to merge into one zone already at a depth of $100 \mathrm{~m}$ (Fig. 13).

The strongest reflections in crystalline bedrock environments often correlate with fracture zones (e.g., Green and
Mair, 1983; Juhlin and Stephens, 2006) or mafic sheets (e.g., Juhlin, 1990). Reflection R1/S1 can be interpreted as originating from a fracture zone. However, the character of reflections R2-R5 appears different from R1/S1. Reflection R1 is 
rather weak and discontinuous, while reflections R2-R5 are stronger and more continuous (Fig. 7). Although no geologic correlation to amphibolite rich gneiss or inter-layered mafics can be made for reflections R2-R5, it is possible that these reflections originate from such rocks since they are present in the area. Nasuti et al. (2011) also observed and sampled amphibolites outside the reported area, indicating a lack of detail in the geological maps. The R2-R5 reflections may, however, also represent secondary fracture zones. Secondary fracture zones are indicated in the shallow subsurface by the low resistivity zones P1-P3 in R.P. 5 (Figs. 13 and 14).

The strongest reflectivity in the area corresponds to gentle antiform structures which have a similar shape on both seismic profiles (Fig. 14). A boundary, where an increase in reflectivity occurs, is located at approximately $1 \mathrm{~km}$ depth in S.P. 2 and at about $0.5 \mathrm{~km}$ in S.P. 1. The antiform structure could be associated with the folded amphibolite rocks present in the northwestern part of S.P. 2. However, these rocks do not appear farther north (on S.P. 1, see Fig. 2) where the antiform is located at a shallower depth in the seismic section. The antiform also appears to be much more gently folded than the folded rocks on the geological map (Fig. 2), and the antiform is marked by strong reflectivity indicating a large impedance contrast (seismic velocity and/or density contrast). Therefore, we interpret this antiform structure as a boundary to a different unit. This unit reflects a significant property change within the gneissic basement rock. One such boundary that could cause a large impedance contrast is the detachment zone separating the lower eclogitic crust from the middle and upper crust exposed in Western Norway (Andersen and Jamtveit, 1990). The fold hinge line of this unit appears to have a strike subparallel to the strike of the Tjellefonna fault (Fig. 14). Unfortunately, it is difficult determine if the fault structures cut the fold structure or not. Reflection $\mathrm{R} 1 / \mathrm{S} 1$ seems to terminate approximately where a continuation of the southeastern flank of the antiform in S.P. 2 is expected. However, there is no obvious reason to why such a fold flank should not be imaged properly in the seismic section (Fig. 4a). The northwest dipping reflectivity marked by the arrow in shot 95 (Fig. 6b), and seen in the stacked section between CMP 1750 and 1800 at about $0.5 \mathrm{~s}$ TWT (Fig. 4a), seems to be the only indication of a continuation of the reflective package towards the southeast. Also on S.P. 1, the fold structure is not imaged southeast of the suggested fault zone (Figs. 3 and 14). Therefore, it seems likely that the fault does cut the antiform structure, although the fault zone is not detected deeper in the seismic section. The depth extent to where reflections R1-R5 can be traced on the stacked section is mainly controlled by the length of the seismic acquisition line and a deeper extension cannot be imaged without extending the seismic profile further southeast. The parallelism of the fold hinge line and the fault trace of the Tjellefonna fault (Fig. 14) suggest that the folding and faulting may have been related. The low topography lineament does not coincide with the Tjellefonna fault in the northeastern side of the
Tingvollfjord (Figs. 2 and 14), perhaps indicating that the Tjellefonna fault is less pronounced towards the northeast.

\section{Conclusions}

The Tjellefonna Fault was imaged using two reflection seismic profiles located on each side of the Tingvollfjord. The fault extends to a depth of at least $400 \mathrm{~m}$ and most likely to at least $1.3 \mathrm{~km}$ on the southern side of the fjord where it was imaged most clearly. The fault dips $50-60^{\circ}$ towards southeast at depth.

A continuation of the fault on the northeastern side is suggested by correlation of an in-strike P-S converted reflection (generated by a fracture zone) seen on the reflection data on the northeastern side of the Tingvollfjord on S.P. 1. The fault zone is, however, not seen on the stacked section on this profile, perhaps due to the fault zone being steeper on the northeastern side or because the seismic profile was too short to image the deeper part of the fault zone.

The fault seems to diverge into at least two zones of intensely fractured bedrock near the surface on the southern side of the Tingvollfjord (S.P. 2 and R.P. 7). The seismic data correlate well with resistivity and other near surface geophysical data presented by Nasuti et al. (2011) and in this paper. Also, the strike of the fault is in agreement with previous large scale interpretation of potential field data by Nasuti et al. (2012). However, the main topographic lineament is only in agreement on the south-western side of the Tingvollfjord, perhaps indicating that the Tjellefonna fault is less pronounced towards the northeast.

An antiform can be seen on both seismic sections (S.P. 1 and S.P. 2). Increased amplitudes of reflections from this structure are found at a depth of about $0.5 \mathrm{~km}$ on the northeastern profile (S.P. 1) and at about $1 \mathrm{~km}$ on the southwestern profile (S.P. 2). The fold hinge line of the antiform is parallel to the suggested Tjellefonna fault, indicating that the folding and faulting may have a causal relationship. The amplitude increase suggests a significant physical property change within the gneissic basement rock. If the antiform structure is penetrated or truncated by the fault or not is, however, not clear.

Acknowledgements. We like to thank Puy Ayarza and two anonymous referees for their useful comments on the manuscript. We are also thankful for discussions with co-workers at the Norwegian University of Science and Technology (NTNU) and the Geological Survey of Norway (NGU), especially Christophe Pascal and Jörg Ebbing. We also thank staff members and students at NTNU, NGU and Uppsala University for all the hard work performed during acquisition. This integrated geological/geophysical study is a cooperation between the Geological Survey of Norway (NGU), NTNU and Uppsala University and was financed by the Norwegian Research Council (NFR-Frinat project 177524: "The Møre-Trøndelag Fault Complex - an integrated study”). GLOBE ClaritasTM under license from the Institute of Geological and 
Nuclear Sciences Limited, Lower Hutt, New Zealand was used to process the seismic data. GMT from P. Wessel and W. H. F. Smith was used to prepare most figures. We also thank the GOCAD Consortium and Paradigm for providing an academic license of GOCAD for 3-D visualization and interpretation of the data.

Edited by: R. Carbonell

\section{References}

Andersen, T. B. and Jamtveit, B.: Uplift of deep crust during orogenic extensional collapse: a model based on field studies in the Sogn-Sunnfjord region, W. Norway, Tectonics, 9, 1097-1111, 1990.

Austrheim, H., Corfu, F., Bryhni, I., and Andersen, T. B.: The Proterozoic Hustad igneous complex: a low strain enclave with a key to the history of the Western Gneiss Region of Norway, Precambrian Res., 120, 149-175, 2003.

Biedermann, A. R.: Magnetic Properties of the Møre-Trøndelag Fault Complex, Msc thesis, ETH Zürich, http://e-collection. library.ethz.ch/view/eth:1986, 2010.

Braathen, A., Nordgulen, Ø., Osmundsen, P. T., Andersen, T. B., Solli, A., and Roberts, D.: Devonian, orogen-parallel, opposed extension in the Central Norwegian Caledonides, Geology, 28, 615-618, 2000.

Brekke, H.: The tectonic evolution of the Norwegian Sea continental margin, with emphasis on the Vøring and Møre basins, in: Dynamics of the Norwegian Margin, edited by: Nøttvedt, A., Geol. Soc. Lond. Spec. Publ., 167, 327-378, 2000.

Cosma, C. and Enescu, N.: Characterization of fractured rock in the vicinity of tunnels by the swept impact seismic technique, Int. J. Rock Mech. Min., 38, 815-821, 2001.

Dahlin, T.: 2D resistivity surveying for environmental and engineering applications, First Break, 14, 275-284, 1996.

Dehghannejad, M., Juhlin, C., Malehmir, A., Skyttä, P., and Weihed, P.: Reflection seismic imaging of the upper crust in the Kristineberg mining area, northern Sweden, J. Appl. Geophys., 71, 125-136, 2010.

Faleide, J. I., Kyrkjebø, R., Kjennerud, T., Gabrielsen, R. H., Jordt, H., Fanavoll, S., and Bjerke, M. D.: Tectonic impact on sedimentary processes during Cenozoic evolution of the northern North Sea and surrounding areas, Geol. Soc. Lond. Spec. Publ., 196, 235-269, 2002.

Gabrielsen, R. H., Odinsen, T., and Grunnaleite, I.: Structuring of the Northern Viking Graben and the Møre Basin; the influence of basement structural grain, and the particular role of the MøreTrøndelag Fault Complex, Mar. Petrol. Geol., 16, 443-465, 1999.

Ganerød, G. V., Grøneng, G., Rønning, J. S., Dalsegg, E., Elvebakk, H., Tønnesen, J. F., Kveldsvik, V., Eiken, T., Blikra, L. H., and Braathen, A.: Geological model of the Åknes rockslide, western Norway, Eng. Geol., 102, 1-18, 2008.

Green, A. G. and Mair, J. A.: Subhorizontal fractures in a granitic pluton: Their detection and implications for radioactive waste disposal, Geophysics, 48, 1428-1449, 1983.

Grønlie, A. and Roberts, D.: Resurgent strike-slip duplex development along the Hitra-Snåsa and Verran Faults, Møre-Trøndelag Fault Zone, Central Norway, J. Struct. Geol., 11, 295-305, 1989.

Grunnaleite, I. and Gabrielsen, R. H.: Structure of the Møre Basin, mid-Norway continental margin, Tectonophysics, 252, 22I-251,
1995.

Hacker, B. R., Andersen, T. B., Johnston, S., Kylander-Clark, A. R. C., Peterman, E. M., Walsh, E. O., and Young, D.: Hightemperature deformation during continental-margin subduction \& exhumation: The ultrahigh-pressure Western Gneiss Region of Norway, Tectonophysics, 480, 149-171, 2010.

Hurich, C. A.: Kinematic evolution of the lower plate during intracontinental subduction: An example from the Scandinavian Caledonides, Tectonics, 15, 1248-1263, 1996.

Hurich, C. A. and Roberts, D.: A seismic reflection profile from Stjørdalen to Outer Fosen, Central Norway: a note on the principal results, Norg. Geol. Unders. B., 433, 18-19, 1997.

Juhlin, C.: Interpretation of the reflections in the Siljan Ring area based on results from the Gravberg-I borehole, Tectonophysics, 173, 345-360, 1990.

Juhlin, C.: Imaging of fracture zones in the Finnsjön area, central Sweden, using the seismic reflection method, Geophysics, 60, 66-75, 1995.

Juhlin, C. and Stephens, M. B.: Gently dipping fracture zones in Paleoproterozoic metagranite, Sweden: Evidence from reflection seismic and cored borehole data and implications for the disposal of nuclear waste, J. Geophys. Res., 111, B09302, doi:10.1029/2005JB003887, 2006.

Juhlin, C., Dehghannejad, M., Lund, B., Malehmir, A., and Pratt, G.: Reflection seismic imaging of the end-glacial Pärvie Fault system, northern Sweden, J. Appl. Geophys., 70, 307-316, 2010.

Juhlin, C. and Lund, B.: Reflection seismic studies over the endglacial Burträsk fault, Skellefteå, Sweden, Solid Earth, 2, 9-16, doi:10.5194/se-2-9-2011, 2011.

Loke, M. H.: Tutorial: 2-D and 3-D electrical imaging surveys, 136 pp., 2004.

Lundberg, E. and Juhlin, C.: High resolution reflection seismic imaging of the Ullared Deformation Zone, southern Sweden, Precambrian Res., 190, 25-34, 2011.

Moos, D. and Zoback, M. D.: In Situ Studies of Velocity in Fractured Crystalline Rocks, J. Geophys. Res., 88, 2345-2358, 1983.

Mosar, J., Eide, E. A., Osmundsen, P. T., Sommaruga, A., and Torsvik, T. H.: Greenland - Norway separation: A geodynamic model for the North Atlantic, Norw. J. Geol., 82, 281-298, 2002.

Mykkeltveit, S.: A Seismic Profile in Southern Norway, Pure Appl. Geophys., 118, 1310-1325, 1980.

Nasuti, A., Chawshin, K., Dalsegg, E., Tønnesen, J. F., Ebbing, J., and Gellein, J.: Electrical resistivity and refraction seismics over a segment of the Møre-Trøndelag Fault Complex, NGU report 2009.037, 37 pp., 2009.

Nasuti, A., Pascal, C., Ebbing, J., and Tønnesen, J. F.: Geophysical characterisation of two segments of the Møre-Trøndelag Fault Complex, Mid Norway, Solid Earth, 2, 125-134, doi:10.5194/se2-125-2011, 2011.

Nasuti, A., Pascal, C., and Ebbing, J.: Onshore-offshore potential field analysis of the Møre-Trøndelag Fault Complex and adjacent structures of Mid Norway, Tectonophysics, 518-521, 17-28, 2012.

Olesen, O., Blikra, L. H., Braathen, A., Dehls, J. F., Olsen, L., Rise, L., Roberts, D., Riis, F., Faleide, J. I., and Anda, E.: Neotectonic deformation in Norway and its implications: a review, Norw. J. Geol., 84, 3-34, 2004.

Osmundsen, P. T., Eide, E. A., Haabesland, N. E., Roberts, D., Andersen, T. B., Kendrick, M., Bingen, B., Braathen, A., and 
Redfield, T. F.: Kinematics of the Høybakken detachment zone and the Møre-Trøndelag Fault Complex, central Norway, J. Geol. Soc. London, 163, 303-318, 2006.

Pascal, C. and Gabrielsen, R. H.: Numerical modeling of Cenozoic stress patterns in the mid-Norwegian margin and the northern North Sea, Tectonics, 20, 585-599, 2001.

Redfield, T. F. and Osmundsen, P. T.: The Tjellefonna Fault system of Western Norway: Linking late-Caledonian extension, postCaledonian normal faulting, and Tertiary rock column uplift with the landslide-generated tsunami event of 1756 , Tectonophysics, 474, 106-123, 2009.

Redfield, T. F., Braahten, A., Gabrielsen, R. H., Osmundsen, P. T., Torsvik, T. H., and Andriessen, P. A. M.: Late Mesozoic to Early Cenozoic components of vertical separation across the MøreTrøndelag Fault Complex, Norway, Tectonophysics, 395, 233249, 2005a.

Redfield, T. F., Osmundsen, P. T., and Hendriks, W. H.: The role of fault reactivation and growth in the uplift of western Fennoscandia, J. Geol. Soc. London, 162, 1013-1030, 2005 b.

Roberts, D.: High-strain zones from meso- to macro-scale at different structural levels, Central Norwegian Caledonides, J. Struct. Geol., 20, 111-119, 1998.

Séranne, M.: Late Paleozoic kinematics of the Møre-Trøndelag Fault Zone and adjacent areas, central Norway, Norsk Geol. Tidsskr., 72, 141-158, 1992.
Sherlock, S. C., Watts, L. M., Holdsworth, R. E., and Roberts, D.: Dating fault reactivation by $\mathrm{Ar} / \mathrm{Ar}$ laserprobe; an alternative view of apparently cogenetic mylonite-pseudotachylite assemblages, J. Geol. Soc. London, 161, 335-338, 2004.

Skår, Ø. and Pedersen, R. B.: Relations between granitoid magmatism and migmatization: $\mathrm{U}-\mathrm{Pb}$ geochronological evidence from the Western Gneiss Complex, Norway, J. Geol. Soc. London, 160, 935-946, 2003.

Sommaruga, A. and Bøe, R.: Geometry and subcrop maps of shallow Jurassic basins along the Mid-Norway coast, Mar. Petrol. Geol., 19, 1029-1042, 2002.

Terry, M. P. and Robinson, P.: Evolution of amphibolite-facies structural features and boundary conditions for deformation during exhumation of high- and ultrahigh-pressure rocks, Nordøyane, Western Gneiss Region, Norway, Tectonics, 22, 1036, doi:10.1029/2001TC001349, 2003.

Tveten, E., Lutro, O., and Thorsnes, T.: Berggrunnskart Alesund, 1:250000, (Alesund, western Norway), Geological Survey of Norway, Trondheim (bedrock map), 1998.

Wain, A.: New evidence for coesite in eclogite and gneisses: Defining an ultrahigh-pressure province in the Western Gneiss region of Norway, Geology, 25, 927-930, 1997. 